\title{
Proceeding
}

Supplementary Issue: Winter Conferences of Sports Science. Costa Blanca Sports Science Events, 22-23 March 2021. Alicante, Spain.

\section{The effects of tactical sequences on game scenarios in the development of skilful and tactical performances for futsal players}

\author{
SADIQ JAFAR SADIQ \\ College of Basic Education, Physical Education and Sports Science, Mustansiriyah University, Baghdad, Iraq
}

\begin{abstract}
The research problem is represented by the weakness in implementing the plans for some playing modes in this game and consequently weakness and decline in the planning and skilful performance for most players. This study aims to make and design practices for tactical sequences for some playing modes in the Futsal game and to learn the effects of these practices in the planning and skilful performances of the research sample. The study hypothesis that there are statistically important differences between the results pre-tests and post-tests in planning and skilful performance for the research of the two groups for the experimental group. Used the experimental method to suit the nature of the problem to be solved and to achieve the objectives and the hypothesis of the research. The main experiment implementation lasted for 6 weeks that contains 3 training learning units. After finishing the main experiment, the posttest was made and used SPSS to treat the results of posttests and pretests for the experiment of the two groups. For the skill and planning performance of the experimental group. Used the experimental method or its suitability to the nature problem to be solved and to achieve the objectives and hypothesis of the research and reach to several conclusions including that the practices of tactical sequences or some modes of playing that are made and corrected by the researcher which had a positive influence in developing the in skilful and planning performance for the subjects of the experimental group.

Keywords: Training; Coach tactics; Futsal; Practices.
\end{abstract}

Cite this article as:

Sadiq, S.J. (2021). The effects of tactical sequences on game scenarios in the development of skilful and tactical performances for futsal players. Journal of Human Sport and Exercise, 16(3proc), S1340-S1350. https://doi.org/10.14198/ihse.2021.16.Proc3.49

Corresponding author. College of Basic Education, Physical Education and Sports Science, Mustansiriyah University, Baghdad, Iraq. https://orcid.org/0000-0001-7455-3271

E-mail: alsadiqjafar1975.edbs@uomustansiriyah.edu.iq

Abstract submitted to: Winter Conferences of Sports Science. Costa Blanca Sports Science Events, 22-23 March 2021. Alicante, Spain.

JOURNAL OF HUMAN SPORT \& EXERCISE ISSN 1988-5202.

(c) Faculty of Education. University of Alicante.

doi:10.14198/jhse.2021.16.Proc3.49 


\section{INTRODUCTION}

As a result, for the development of sciences and knowledge in many sports fields such as football, this game took the great interest of the researchers that was reflected on the development of the playing styles, plans, and laws that aims to teach the individual to acquire and master the movement skilfully. Among the developments, skill is one of the game derivations as it is a basic element to develop as well as it is a skill, plans, events and unexpected attitudes in the match which provoke everybody to practice and to watch because of its easy rules, a little field of play, small number of players and similar basic skills as is with football. That is because the game is practiced by a great number of players as it is considered one of the games that need preciseness and generalization of movement skills of this game, especially mastering the game modes that are the key to reach the competitor's goal and scores through the tactical sequences that are implemented in the leaning training units. Some coaches think that the performance of the match depends on the player's skills, physical and psychological situations and to leave the movement in the field and the planning for the players experience. It was scientifically proven from the experience in the playfields that this type of training imposes suffering to the players during the game for there is no unity of thinking that makes them behave as a unit, of good planning behaviour in front of the competitor. Here comes the importance of the research through the practice of certain planned movement sequences that imitate some real playing cases and to learn its influence on the development of the skilful and planning performance of Futsal players.

\section{Research problem}

Upgrading the reality of various sports requires the concerned parties to pay attention to the positive aspects of their promotion and to the negative aspects to treat them and the futsal football game is one of the games that have taken confident steps and this progress made in this game was not improvisation or a pure coincidence, but rather was the result of scientific programmed planning according to valid contexts, through effective use of the results of research and studies that have been conducted by countries that seek development.

And because the researcher were players of this game and, for in many Premier Clubs previously and he is working in the field of this game currently, they found that there is a weakness in the implementation of plans for some cases of playing in this game and therefore there is weakness and low performance and skilful planning for the common players so they put exercises for tactical movement sentences for some cases the toys are intended to improve the players' performance skilfully and strategically, as they represent an important step to integrate the preparation skills and the skilful planning.

\section{Research objectives}

1. Setup and design practices for tactical sequences for some cases of play that are compatible with the capabilities of the research sample.

2. Knowing the effects of these practices on the skilful and planning performance of the research sample.

\section{Research hypotheses}

1. There are statistically significant differences between the results of the pretests and post-tests of the two research groups and in favour of the post tests in the skilful and planning performance.

2. There are statistically significant differences in the results of the post-tests between the two research groups and in favour of the experimental group in the skifful and planning performance. 


\section{Research fields}

The Human Fields: Baghdad Club players are participating in the Premier League Futsal for the 2017-2018 season.

Spatial Field: The Roofed Hall of Al-Adhamiya Sports Club.

Time Field: The study spanned from 13/1/2018 to 3/3/2018.

\section{Terminology}

The Tactical Kinematic Sequences: They are a set of attack and defensive movements which planned individually or by group of players and other actions that aimed to obtain better result in the game and according to the rules of the game (Alam, 2018).

Skilful Performance: "It is the ability of the player to learn and master the performing of one skill or a set of basic skills in the futsal sport in a coherent, smooth and error-free manner in real competition conditions, whether in a real match or in competition-like situations such as being under the pressure of a competitor or the speed factor and time during performance" (Sadiq, 2016).

\section{RESEARCH METHODOLOGY}

The researcher used the experimental approach to suit the nature of the problem to be solved and to achieve the goals and hypotheses of the research.

\section{Research society and its sample}

The research society was determined by the players of Baghdad clubs participating in the Halls Football Premier League for the season 20017-2018, which numbered (6) clubs and the number of players in these clubs is (81) players. The researcher extracted two clubs by lottery from them, one of them as an experimental group is (Masafi Alwasat Club) and the other is a (Jensia Club) also held by lottery, and the total number of players for them was (26) players. Thus, the ratio of the sample to the research society reached (32.09\%). The researcher excluded several players to achieve consistency in the groups, and the excluded players are:

1. Injured players who do not attend the practice, which numbered (4) from Masafi Alwasat Club.

2. Experienced players whose training ages are older than their colleagues in the club are (2) from Jensia Club.

Homogeneity of the Sample (Table 1):

Table 1. Explains the sample subjects.

\begin{tabular}{cccccc}
\hline Variables & Unit Measurement & Mean & Std. Deviation & Median & Skewness \\
\hline Length & Centimetre & 176.8 & 3.1 & 177 & -0.098 \\
Mass & Kilo Gram & 72.65 & 6.69 & 72.5 & 0.275 \\
Training Age & Month & 42.6 & 11.33 & 36 & 0.257 \\
\hline
\end{tabular}

\section{Methods of gathering information, devices and tools used in the research}

Data collection tools

For the researcher to accomplish their experiment, some methods and tools that help them in carrying out the experiment and completing the research must be used, Thus the researcher used the following research tools and means: 
1- Arab and foreign sources.

2- Personal interviews.

3- Observation and experimentation.

4- The form of data collection and information writing down.

5- Tests and measurements.

Devices and auxiliary tools used in the research

The researcher benefited from the following devices and tools:

1- Five-Players standard balls, (12) balls.

2- The Roofed Hall of Al-Adhamiya Sports Club.

3- Poles of different heights, number (24).

4- Coloured adhesive tape to line and define the test areas.

5- A tape measure of length (made of leather) (one meter and its parts) with a length of (20) meters.

6- Japanese origin Canon camera.

7- Chinese (2) stopwatches.

8- Whistle number (2).

9- Small Whiteboard and coloured pens.

10- Flex board for recording the score.

11- A balance for measuring mass.

Field research tests

The first test: the name of the test: the planning connection test with changing direction and adjusted scoring (Salim, 2018).

Purpose of the test

Speed and accuracy of planning performance.

Recording: Dividing the total of accuracy points by the total time of the player's performance.

The second test: The name of the test: Valid test of skilful performance (Sadiq, 2016).

Test objective: To measure the skilful performance in futsal football.

Scoring: Calculate the player's total performance time on the three test stations and the best is the lowest time.

\section{Exploratory experiment}

The First Exploratory Experience: The researcher conducted the first exploratory experiment on 23/12/2018 for research tests on a sample of 5 players representing Baghdad Club who are out of the research sample and the purpose of this experiment was:

Learning how to perform each test, how difficult it is and highlighting the obstacles that the researcher will face upon implementation.

Ensuring the safety of the devices and tools used in performing the test.

Training the assistant work staff on how to administer the test and record its results.

Learning the time spend to perform each test. 
The Second Exploratory Experience: The second exploratory experiment was conducted on 28/12/2017 on 5 other players representing Baghdad Club participating in the Futsal Premier League for the 2017-2018 season. The purpose of this experiment was to extract scientific coefficients and conditions for the two research tests, and the same tests were on the same players and under the same conditions on 4/1/2018.

The scientific basis for the tests

Test Reliability: To calculate the reliability test coefficients, the researcher adopted the test and retest method, according to all tests, based on the experimental pilot sample, on 28/12/2017 and the same tests were repeated after (7) days on 4/1/2018. Then the data were treated by measuring the Pearson correlation coefficient between the scores of each of the two tests, and the measured correlation results showed that there is a good correlation relationship between the tests.

Note: $(76 \%)$ for planning connection and $(82 \%)$ for skilful performance.

Validity of the Test: The researcher used the self-validity coefficient to confirm the validity of the test. Selfvalidity is measured by calculating the square root of the reliability coefficient of the test.

$$
\sqrt{\text { self }- \text { validty }=\text { Test stability coefficients }}
$$

Note: $(0.87 \%)$ for planning connection and $(91 \%)$ for skilful Performance.

The Objectivity of the Test: The approved tests were clear, understandable, and far from the self-assessment of the estimator, as the registration is carried out with the approval of time units and the number of times of success (the degree), and the specific instructions for each test were clearly defined and the conditions applicable during implementation were affixed, In addition to the fact that the auxiliary team of specialists in physical education experts and thus the accredited tests are highly objective.

Pre-Tests: The researcher conducted the pretest for the research, two tests of the experimental group at exactly one pm on Wednesday, 11/1/2018, and in the Roofed Adhamiya Club Hall. On the second day, the researcher conducted the tests on the control group.

Sample Equivalence: The researcher extracted valence values for the experimental and control groups using the results of their tests that they obtained in the pretest, as shown in (Table 2).

Table 2. Explains T-test to find the valence between the research two groups in the posttest.

\begin{tabular}{|c|c|c|c|c|c|c|}
\hline \multirow{2}{*}{ The research test } & \multicolumn{2}{|c|}{ Experimental group } & \multicolumn{2}{|c|}{ Control group } & \multirow[b]{2}{*}{ Counted T value } & \multirow{2}{*}{ Significance } \\
\hline & Mean & $\pm S D$ & Mean & $\pm \mathrm{SD}$ & & \\
\hline $\begin{array}{l}\text { Choosing the planning } \\
\text { connection test }\end{array}$ & 0.717 & 0.215 & 0.680 & 0.216 & 0.394 & .703 \\
\hline $\begin{array}{l}\text { Choosing skilful } \\
\text { performance testy }\end{array}$ & 57.02 & 19.83 & 44.36 & 4.85 & 2.023 & .074 \\
\hline
\end{tabular}

The Main Experience: The researcher made various tactical sequence practices distributed by (4) practice of planning sequences for some playing cases. After that, these practices were applied to the experimental group represented by the Masafi Alwasat Club players participating in the Futsal Premier League for the 2017-2018 season, knowing that the main experiment was applied on them in the period of the stop of the 
league between the two rounds, which extended to 3 months due to the participation of the national team, the youth team and the Masafi Alwasat Club with international competitions. The experiment was implemented by 3 units per week to give one playing case that means one practice for one tactical sequence in each training unit by one in its main section only and this schematic sequence is repeated within the main section and for all players by dividing them into the stations of each station that implements a total tactical sequence and the players are moved from one station to another at a specified time after which they are implemented during play by conducting a match between the players for 10 minutes is in it the feedback and correction took the main experiment 6 weeks distributed as shown in (Table 3).

Table 3. Represent the number of experiments weeks, days of learning training units, type and number of tactical sequences.

\begin{tabular}{|c|c|c|c|}
\hline $\begin{array}{l}\text { Practices } \\
\text { weeks }\end{array}$ & Days of training units & No. of tactical sequences & Types of sequences \\
\hline First week & $\begin{array}{l}\text { Saturday-Monday- } \\
\text { Wednesday }\end{array}$ & A sequence for playing case & Case play $(A)$ \\
\hline Second week & $\begin{array}{l}\text { Saturday-Monday- } \\
\text { Wednesday }\end{array}$ & $\begin{array}{l}\text { One sequence for playing } \\
\text { case }\end{array}$ & Case play $(\mathrm{C})$ \\
\hline Third week & $\begin{array}{l}\text { Saturday-Monday- } \\
\text { Wednesday }\end{array}$ & $\begin{array}{l}\text { One sequence for playing } \\
\text { case }\end{array}$ & Case play (B) \\
\hline Fourth week & $\begin{array}{l}\text { Saturday-Monday- } \\
\text { Wednesday }\end{array}$ & $\begin{array}{l}\text { One sequence for playing } \\
\text { case }\end{array}$ & Case play (D) \\
\hline Fifth week & $\begin{array}{l}\text { Saturday-Monday- } \\
\text { Wednesday }\end{array}$ & $\begin{array}{l}\text { One sequence for playing } \\
\text { case. } \\
\text { One sequence for playing } \\
\text { case }\end{array}$ & $\begin{array}{l}\text { Repeating Case play } \\
\text { (A) } \\
\text { Repeating Case play } \\
\text { (C) }\end{array}$ \\
\hline Sixth week & $\begin{array}{l}\text { Saturday-Monday- } \\
\text { Wednesday }\end{array}$ & $\begin{array}{l}\text { One sequence for playing } \\
\text { case. } \\
\text { One sequence for playing } \\
\text { case }\end{array}$ & $\begin{array}{l}\text { Repeating Case play } \\
\text { (B) } \\
\text { Repeating Case play } \\
\text { (D) }\end{array}$ \\
\hline
\end{tabular}

Post-Tests: After finishing the practices on 3/3/2018 which lasted (6) weeks and for the purpose of determining the level at which the research sample reached (experimental and control), the posttests were conducted for the two groups (experimental and control), on 12/3/2018 AD in the roofed Adhamiya Sports Club hall, and I followed the same conditions and procedures that were followed in the tribal tests in order to control the variables that affect the results of the experiment.

Statistical means: The researcher used the statistical bag (SPSS) on the computer to process all the research data for the following statistical laws:

Simple correlation coefficient (Pearson). Arithmetic mean.

Mediator. standard deviation.

Coefficient of torsion. (T) Law for correlated samples.

\section{RESEARCH FINDINGS}

Presenting, analysing and discussing the results

Present, analyse and discuss the results of pre- and post-tests of the experimental group. 
Present and analyse the results of pre and posttests of the experimental group: This section includes the presentation and analysis of the results of both the pre and posttests which were reached through statistical treatments in the light of the tests used in research.

Table 4. Explains the mathematical mean, standard deviations and t value measured for pre- and post- tests for experimental group.

\begin{tabular}{|c|c|c|c|c|c|c|}
\hline \multirow{2}{*}{ The research test } & \multicolumn{2}{|c|}{ Pre-test } & \multicolumn{2}{|c|}{ Post-test } & \multirow{2}{*}{ Counted T value } & \multirow{2}{*}{ Significance } \\
\hline & Mean & $\pm S D$ & Mean & $\pm S \mathrm{SD}$ & & \\
\hline $\begin{array}{l}\text { Choosing the planning } \\
\text { connection test }\end{array}$ & 0.717 & 0.215 & 1.1 & 0.172 & 6.139 & .000 \\
\hline $\begin{array}{l}\text { Choosing skilful } \\
\text { performance testy }\end{array}$ & 57.02 & 19.84 & 41.33 & 3.16 & 2.753 & .022 \\
\hline
\end{tabular}

When observing (Table 4), He finds that the value of the degree (sig) is smaller than the standard significance level $(0.05)$ in the linear correlation test, and this indicates the significance of the differences in favour of the post-test. A score (sig) recorded a value smaller than the standard significance level in the skilful performance test. This indicates the significance of differences in favour of the posttest, as shown in (Figure 1).

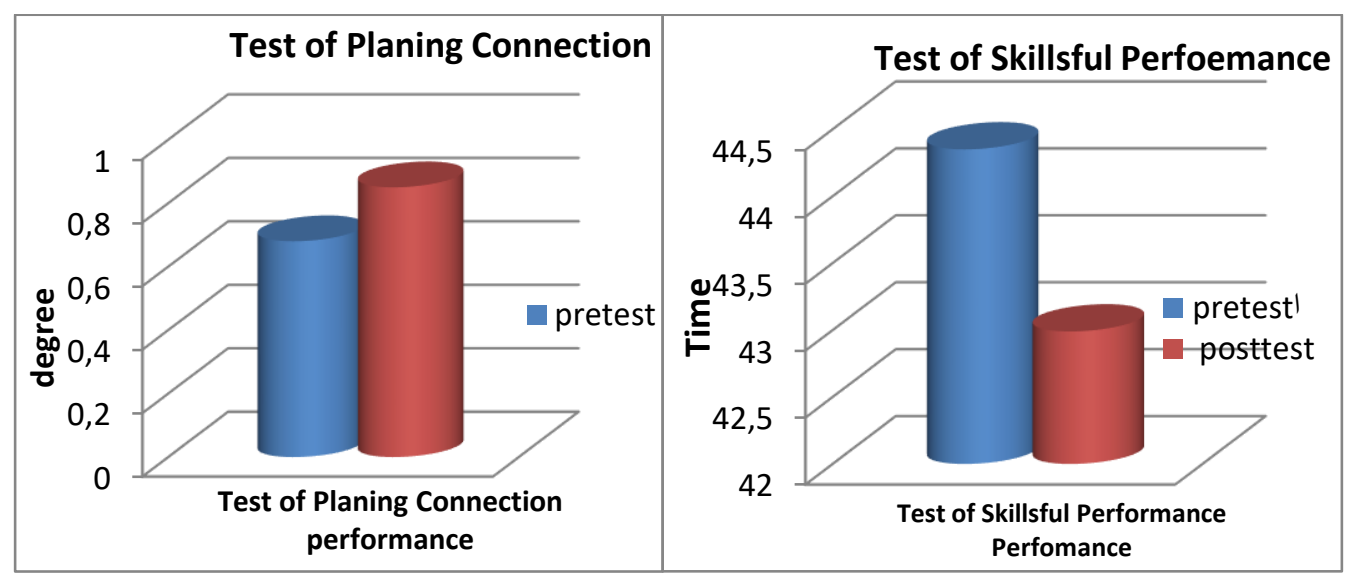

Figure 1. Explain the mathematical means for pre-and post -tests for the excremental group in the researched tests.

Discussing the results of the pre and posttests of the experimental group: Through our observation of (Table 5) and (Figure 1), we find that there is development in all the variables that this study was interested in studying, which led to the significance of the differences in all of them, and these results confirm the high ability of the proposed practices that are based on preparing and designing practices for tactical sequences for some cases of play, the purpose of which is to develop the level of performance of the research sample in terms of skilful and plans. The researcher believe that the progress made for the group of variables under study clearly led to the development of the skilful performance of the player because these exercises were prepared and designed in a way that simulates what is actually happening during play If it included exercises to roll the ball and move it from one place to another and with many iterations and from different situations, the player's ability to master the skilful and control is increased, and this is in line with what Mufaq Mawla referred to, "Rolling practices are the ones linking between putting the ball and stopping and turning and changing the path of the ball and deception With the exercises, moving the ball from one place to another increased the player's ability to master the skill" (Al-Mawla, 1990), and these practices were prepared on the 
basis of tactical sentences that closely resembled the requirements of the futsal game in terms of emphasizing manipulations as the backbone of team play, especially ground manoeuvres. A fast and accurate way to secure its arrival in the teammate increased the player's experience of handling and speed of reaching the competing goal and with high accuracy, and this is what Razzaq Hussein referred to. "The five-soccer game prefers training on the ground and strong passes, and it is one of the fastest manoeuvres because it reaches the teammate as quickly and is widely used in playing and building attacks due to the ease of controlling the ball, which leads to the implementation of attacks in the shortest possible time before the opposing team organizes its defence" (Al-Musawy, 2012) and also was taken into account when preparing these. The practices need to end with scoring and with many repetitions that increased the visibility and clarity of the player in how to control the ball during attacks on the opponent's goal as a result of drawing the image of correct performance in the mind, which increased the player's ability to score goals. Encouraging taking the right position first, and then the tactic, which is one of the most important basics of the game, which players must master because the main goal in five-a-side football is scoring goals. (Ahmed, 2005) And by mastering these proposed practices, the skill level of each research sample has increased, and so has the level of their plans, through the distribution and good division of these exercises, which were laid out in the form of tactical movement for some cases of play, and this rise and development was progressive, consistent and in line with it, because "play and formation plans considered by some to be one of the components of tactics in football and it is the most prominent element in the team's distinction from others. "The difference is that it is always the renewable and innovative element, as it represents the opponent's surprise with a style of play that is different from what he expects to create an opportunity to reach the goal and score " (Sabur, 2016).

Presenting the Results of pre-post Tests for Control Group, Analyse and Discussing them Presenting the Results of pre-post Tests for Control Group and Analyse them.

Table 5. Explain the mathematic mean, standard deviations and t value measured for pre- and post- tests for control group.

\begin{tabular}{lcccccc}
\hline \multirow{2}{*}{ The research test } & \multicolumn{2}{c}{ Pre-test } & \multicolumn{2}{c}{ Post-test } & \multirow{2}{*}{ Counted T value } & \multirow{2}{*}{ Significance } \\
\cline { 2 - 5 } & Mean & $\pm S D$ & Mean & \pm SD & \\
\hline $\begin{array}{l}\text { Choosing the planning } \\
\text { connection test }\end{array}$ & 0.68 & 0.216 & 0.85 & 0.189 & 5,28 & .001 \\
$\begin{array}{l}\text { Choosing skilful } \\
\text { performance testy }\end{array}$ & 44.35 & 4.85 & 42.99 & 3.27 & 2.44 & .037 \\
\hline
\end{tabular}

When observing (Table 5), we find that the value of the degree (sig) of the linear correlation is smaller than the standard significance level, and this indicates the significance of differences for the benefit of the post test. As shown in (Figure 2).

Discuss the results of the pre and posttests of the control group: Through our observation of (Table 6) and (Figure 2), we find that the control group has achieved development in all research variables, which led to the significance of the differences for the variables of the linear link and skilful performance, and the researcher attribute the reason for the occurrence Significant differences in the research variables, the linear link and the skilful performance that the training method used for the control sample has achieved this development, which led to a statistically significant difference, and although all the control group variables have recorded a development between the pre and post-tests for them, they were much less than the development of the experimental group T. J. The exercises prepared by the researcher were used by the two 
groups to achieve statistically significant differences between the pre- and post-tests, thus achieving the first hypothesis that the researcher assumed.

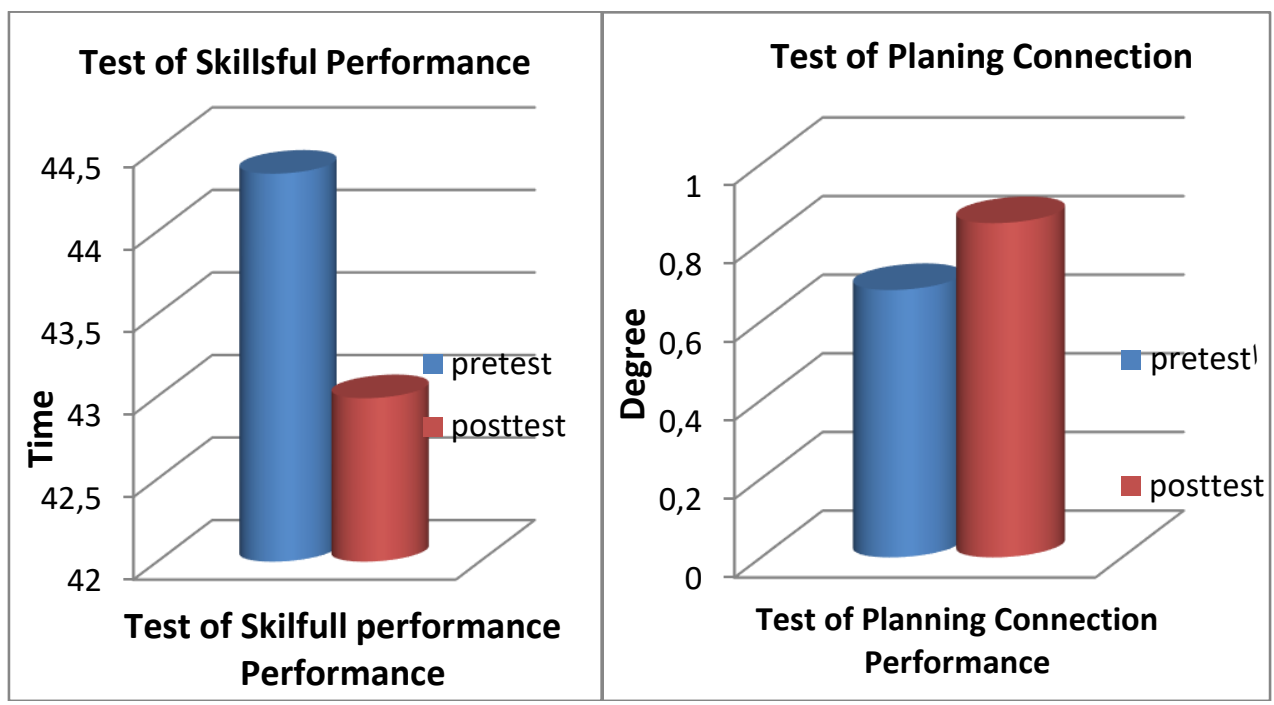

Figure 2. Explain the mathematical means for pre and post tests for the excremental group in the researched tests.

Presenting, analysing and discussing the pre- and post-test results of the research two groups.

Presenting and analysing the results of the post test for the two research groups.

Table 6. Explain the arithmetic mediums, standard deviations and $T$ value measured for posttest for experimental group.

\begin{tabular}{|c|c|c|c|c|c|c|}
\hline \multirow{2}{*}{ The research test } & \multicolumn{2}{|c|}{ Experimental group } & \multicolumn{2}{|c|}{ Control group } & \multirow{2}{*}{ Counted T value } & \multirow{2}{*}{ Significance } \\
\hline & Mean & $\mathrm{SD} \pm$ & Mean & $\mathrm{SD} \pm$ & & \\
\hline $\begin{array}{l}\text { Choosing the planning } \\
\text { connection test }\end{array}$ & 1.1 & 0.172 & 0.85 & 0.189 & 3.3 & .009 \\
\hline $\begin{array}{l}\text { Choosing skilful } \\
\text { performance testy }\end{array}$ & 41.33 & 3.16 & 42.99 & 3.27 & 1.89 & .304 \\
\hline
\end{tabular}

When observing (Table 6), we find that the value of the degree (sig) of the planning correlation variable is smaller than the standard significance level $(0.05)$, and this indicates the significance of the differences between the two groups' performance in the posttest of this variable and in favour of the experimental group. The degree (sig) recorded a value greater than the standard significance level, which indicates that no significant difference was recorded in this variable.

Discussing the results of the post-test tests for the two research groups: Through our observation of (Table $6)$.

\section{DISCUSSION}

The researcher found that the experimental group outperformed the control group in planning performance, while no statistically significant differences were recorded in the skill performance versus the control group, 
and the researcher attributed the reason for the superiority of the experimental group in the performance plan to the effectiveness of the practice prepared and designed by the researcher and its positive effect, as it was prepared. In a scientific way that simulates what is happening inside the competition as much as possible and corresponds to the capabilities of the research sample through good distribution and division. Among these practices that have been developed in the form of tactical movement sequences for some cases of play, their importance lies in the fact that they surprise the competitor with a style of play that differs from what he expects to create opportunities to reach the opponent's goal and score it, and because the registration process in it $h$ announces greater participation in these practices and positions Different and varied playing situations, all of this resulted in the experimental group registering a clear outperformance in performance and connectivity. According to the terms of skilled performance, the reason for the absence of statistically significant differences between the two research groups is attributed by the researcher to the fact that the members of the two research groups are players participating in the Futsal Premier League, and therefore they are from the category of applicants and therefore their skill levels are very close except for individual differences between Individuals. This is a general condition present in all sports and games, although the athletic average of the experimental group in the skilful performance test had scored a preference compared to the control group, this superiority did not rise to make a significant difference in performance and that the experimental group outperformed in one variable of Two studies were included in this study, and the second hypothesis that the researcher assumed was fulfilled.

\section{CONCLUSION}

After the results were presented, analysed, and discussed, the researcher concluded the following conclusions: The tactical movement practices of some play cases were made and designed by the researchers and have had a positive effect on the development of the planning and skilful performance of the experimental group members. It was found that the followed method applied to the members of the control group also had a positive effect on the development of their planning and skilful performance. It was found that the experimental group was better than the control group in the planning performance. It was found that the skilful level of the two groups in the skilful performance of futsal football.

\section{RECOMMENDATIONS}

In light of the results obtained, the researcher recommends the following:

1. Work to benefit from the results of this study using the tactical sequence practices made and designed by the two researchers in developing the level of skills and planning performance of the futsal soccer players.

2. The researcher recommends the necessity to focus on designing and made various practices from different situations similar to the competition conditions for scoring skills inside the training unit for the futsal soccer teams.

3. The researcher recommends the necessity of reviewing and updating the approved training curricula for the Futsal League clubs and clubs in the futsal football by containing practice for new tactical sequences that are compatible with the capabilities of their players.

4. Make similar research and studies using new practices for tactical sequences for fixed cases and some cases for playing sports in open football fields.

5. Working on building other tests to measure the skills and tactical performance of futsal soccer players, since the researcher has found great difficulty in finding tests for futsal players in measuring skilful and tactical performance. 


\section{REFERENCES}

Ahmed I. (2005), Tactic and technique in Futsal, Baghdad: National library, P. 88-95.

Alam I. (2018), Tactics of Football, Cairo: Cairo Modern Library, P. 154-188.

Al-Mawla M. (1990), the Functional Preparing for Football the Training Physiology -methodology and training, Cairo: Arabic Thinking House, P. 256-280.

Al-Musawy R. (2012), The Influence of Complex Practices on Developing and Bearing skillful Performances in Futsal (Master Thesis), 39. Basra, College of Physical Education and Sports Science: University of Basra, P. 39-65.

Sabur Q. (2016), Scheduling of Training and Planning Performance. Baghdad: Almanahij for Publishing, P. 178-196.

Sadiq S. (2016), Designing a Test to Measure Sport Skill Performance for Futsal, The Swedish Journal of Scientific Research, 3(6): 2-8.

Salim A. (2018), The Influence of Practices similar to play according to the style of cognitive favor in the movement satisfaction and perform some skillful and plans in Juveniles Football (PhD thesis), Baghdad, College of basic Education: Mustansiriyah University, P. 74-100.

\section{(c) $(\mathrm{B})(\mathrm{EY}$}

This work is licensed under a Attribution-NonCommercial-NoDerivatives 4.0 International (CC BY-NC-ND 4.0). 